\title{
Prosody as a Tool for Assessing Reading Fluency of Adult ESL Students
}

\author{
Seftirina Evina Sinambela*
}

English Applied Linguistics Program, State University of Medan, Indonesia

Corresponding Author: Seftirina Evina Sinambela, E-mail: sefti.nambela@gmail.com

\section{ARTICLE INFO}

Article history

Received: September 05, 2017

Accepted: October 18, 2017

Published: December 30, 2017

Volume: 8 Issue: 6

Advance access: December 2017

Conflicts of interest: None

Funding: None

Key words:

Prosody,

Reading Fluency,

Students,

Comprehension

\begin{abstract}
The prosodic features in reading aloud assignment has been associated with the students' decoding skill. The goal of the present study is to determine the reliability of prosody for assessing reading fluency of adult ESL students in Indonesia context. The participants were all Indonesian natives, undergraduate students, adult females and males who have learned English in school (at the very least twice a week) for more than 12 years. Text reading prosody was assessed by reading aloud task and the students' speaking manner was taped and measured by using the Multidimensional Fluency Scale, as for text comprehension was assessed with a standardized test. It was discovered by the current study that prosody is a reliable sign to determine reading fluency and also reading comprehension. The student who did not read the text prosodically (with appropriate expression) actually showed that he/she failed to comprehend the text. This study also revealed that a struggling reader was also having low comprehension capacity in listening spoken texts. The ESL students' common problems to acquire prosodic reading skill are low exposure to the target language and do not have a good model to imitate prosodic reading.
\end{abstract}

\section{INTRODUCTION}

Prosody is the melody of our language. Some anthropologists have even claimed that our melodious speaking manner is possibly served as the origin of music itself (Simpson, Oliver, \& Fragaszy, 2008). Prosody is important because it really matters how a sentence is spoken. Prosody is the variety in pitch (intonation), patterns of accentuation, and also speaking duration that present a text expressive reading (Allington, 1983; Dowhower, 1991; Schreiber, 1980, 1991). Once these characteristics are existing and acceptable in oral reading assignment, the reader is reading prosodically, or "with expression" or communicatively.

An essential task in fluent reading is to provide the characteristic of prosody in a text, even though they are not visually present (Schreiber, 1980). Some studies suggest that prosody is a sign of comprehension, and prosodic reading is a bench mark for reading fluency, but most of the studies in prosody have been conducted on English speaking participants, with elementary grade students as their subjects.

This study investigated the function of prosody in reading comprehension and reading fluency. The research subjects are 10 adult ESL undergraduate students, Indonesian native speaker who has learned English for more than 12 years. Although they are all adult who capable to read well, they often read a text word by word with a monotonous voice without good articulation. This is a characteristic of struggling reader. A fluent reader should be able to read with appropriate prosody since it confirms that reader comprehends his readings (Kuhn \&Stahl, 2000).

With this assumption, these students supposedly unable to comprehend the text thus they cannot answer the questions related to the given texts. But in this particular class, they were able to answer most of the multiple choice questions correctly. Is it possible that for an adult ESL student, the prosody reading does not necessarily relate to comprehension? In the current study, the researcher will observe students' text reading prosody skill through reading aloud task, recording, and scoring.

The researcher chose the reading aloud task in this study for some reason, reading aloud can lighten the tension of having to think what to say, hence enable the students to pay more attention to their speaking manner. Reading aloud could provide the safe environment for the shy students to practice their speaking skill. This task may also benefited visual learners to connect what they see to the sound they hear (Sally Gibson, 2011). Thus, reading aloud is not merely for younger ESL students as in primary grade level but this task is very useful in adult ESL students' class as well. To measure their comprehension skill in spoken text, these students were given a listening comprehension test. 
This led to the following research question:

1. What is the role of prosody in reading fluency and comprehension of adult ESL students?

2. Is there any relation between students' listening and reading comprehension skill?

\section{LITERATURE REVIEW}

\section{Prosody}

Prosody is a linguistic expression to represent the musical and colors of tone of speech; the melody of spoken language. These components indicate many meanings of those spoken words such as: question, surprise, and exclamation. Prosody is important because it really matters how a sentence is spoken. The phrase 'A slice of cheese cake and coffee' means one thing if it is said with a distinct pause (a prosodic phrase boundary) after cheese and quite another thing if the boundary appears after cake. The use of prosody also has the power to shape the meaning of spoken text, such as the emphasis put on certain words when a person speaks. An example: 'I wanted a MEDIUM rare steak, not rare steak' after the waiter served him a plate of rare steak. Another sample of prosodic characteristic is the utilization of the pitch. We usually raise the pitch when asking a question, while, at the moment we make a statement, the pitch usually lowers at the end of the sentence (Peppe et al., 2010).

\section{Reading}

Reading is a complicated cognitive process. A reader builds his/her interpretation of the text while she/he reads. In the last 20 years, advances in theory and research have refined our comprehension of this complex reading process. Each reading researchers surely have their own theories about the exact nature of the processes involved in reading skill, but it is commonly agreed that the most important elements in reading skill are word recognition and comprehension (Kim and Goetz, 1995).

\section{Reading Fluency and Comprehension}

Reading fluency is one of the essential qualities of a good reader, and a lack of fluency is a common attribute of poor readers. The distinction in reading fluency not only contrast good readers from poor but an absence of reading fluency is also a sign of reading comprehension problems (Stanovich, 1991). Fluent reading consists of three important key elements: an accurate reading of connected text at a conversational rate with proper expression (Hudson, Mercer, \& Lane, 2000). A fluent reader has the ability to sustain his/her focus for long periods of time; he/she do not need any particular practice to keep the reading skill. A fluent reader is also able to read in an effortless, flowing manner.

Every aspect of fluency directly related to text comprehension. To read incorrectly the words can lead to misinterpretations of the text since the reader will not able to grasp the author's intended meaning. Slow and laborious reading through the text reduces the reader capacity to create correct interpretation of the text. The lack of prosody skill can lead to improper groupings of words and phrasing. The words became meaningless and the reader will gain nothing from his/ her readings.

\section{Related Researches on Prosody}

A Study in the 2002, conducted as part of the National Assessment of Educational Progress (NAEP), called oral reading fluency study; it is found that when children read and make mistakes that change the meaning of the text, their comprehension toward that text will be low. The researcher also discovered that mistakes that have no impact to meaning are rare.

The capability to construct meaning from printed text is determined by the growth of word recognition skill and reading fluency, it is suggested that these two things should be routinely assessed in the classroom. The teacher may also show the students a good model in prosodic reading. Who could be a good model for prosodic reading? They are professionals speakers, such as television newscasters, or radio announcer who truly read as they speak (Esser \& Polomski, 1988).

\section{Measuring Students' Prosody Skill}

The teacher can assess the reading prosody skill by observing the students' performance in oral reading task. During the text reading a teacher can listen to the rise and fall of the student's voice, expression, and also their way in grouping words in the text.

A quantifiable scale that provides a score that can be used to asses students' reading prosody skill in a class or school can be found in the Multidimensional Fluency Scale (Rasinski, 2004). This current study use the scale as one of instrument to measure prosody skill.

\section{METHOD}

\section{Subjects}

Participants were 10 undergraduate students; all were taking English course in a language center in Medan, North Sumatera, 6 females and 4 males. Their average age was 23 years old. They were all native speaker of Indonesian language and reported no history of neurological or psychological problems.

\section{Material}

- Students' recorded voice in reading aloud assignment.

Data sample:

A student read aloud a short text taken from Longman TOEFL Preparation Course book. Recorded on March 21,2017 at 19.50 WIB.

Eskimos (paused) require (paused) efficient and (paused) proper way (paused) to travel through water (paused) in the...in depth. (Uncertain voice) the areas were [whereteacher correction] where they live (paused) or surrounded 
(paused) by ocean (paused) bays and inlets and (paused) dotted with likes (supposed to be lakes) and (paused) seas (full stop) Two different types of (paused) boat (paused) have been developed by (paused) the eks... the eskimos (paused) It's different to meet specific (paused) [constructed-teacher correction] constructed to meet (paused) specific need (paused) the kayak (pause) is something like (paused) the kanoe (elevated tone as in question) that has been (paused) covered. covered by a deck (full stop with uncertain voice)

- Students' score in answering the questions related to the text.

The sample of question:

\section{PASSAGE 1}

Cardamom is not as widely used as a spice in the United States as it is in other parts of the world. This fruit of ginger plant provides oil that basically has been used solely as a stimulant in American and English medicines. Other cultures have recognized the multipurpose benefits of this aromatic fruit. In Asia it is used to season sauces such as curry; in Middle Eastern countries it is steeped to prepare a flavorful golden-colored tea; in parts of Northern Europe it is used as a spice in various types of pastry.

1. The word "solely" in line 2 could best replace by (A) initially (B) only (C) reportedly (D) healthfully

2. "Curry" in line 4 is

(A) The fruit of ginger plant (B) A spicy sauce (C) $A$ culture of Middle East (D) A golden tea

3. The word "steeped" in line 5 is closest in meaning to

(A) soaked (B) dried (C) stored (D) grown

(Deborah Philips. (2004) Longman Preparation Course for the TOEFL test.p.298)

- Students' score in listening comprehension assignment.

The sample of question:

Part A

On the recording the students heard:

(man) That exam was just awful

(woman) Oh, it could have been worse

(narrator) What does the woman mean?

In the test paper, the students read:

(A) The exam was really awful (B) It was the worst exam she had ever seen

(B) It couldn't have been more difficult (D) It wasn't that hard.

(Deborah Philips. (2004) Longman Preparation Course for the TOEFL test.p.483)

\section{Instrument}

Multidimensional Fluency Scale by Rasinski and standardized test for text comprehension.

\section{Technique of Collecting Data}

- Observation

- Recording

- $\quad$ Scoring

\section{Technique of Analyzing the Data}

Subjects were given 5 novel texts and then were asked to read each text out loud. The reading aloud performance was recorded on a recorder to score text reading prosody at a later time. This was carried out using the Multidimensional Fluency Scale (Rasinski, 2004).

This scale consists of the following four sections:

- Expression and volume (the lowest score point is [1] which means little sense of making text sound like natural language to the highest score [4] which means varies expression and volume to match interpretation of the passage)

- Phrasing (the lowest score point is [1] which means often reads word-by-word to the highest score [4] which means generally reads with good phrasing)

- Smoothness (the lowest score point is [1] which means often make prolonged pauses, false starts, sound outs, and hesitations to [4] which means generally reads smoothly, resolves word and sentence structures quickly)

- $\quad$ Pace (the lowest score point is [1] which means reads slowly and laboriously to [4] which means consistently reads at conversational pace).

Performance on each section was marked on a scale from 1 to 4 . Scores per text thus ranged from 4 to 16 . To answer the second research question, each subject will hear a short conversation recording, spoken by native, and then answered the questions based on the recordings. The text and the recorded short conversation are taken from Longman TOEFL preparation course book.

\section{RESULTS AND DISCUSSION}

From the Table 1, 9 subjects were struggling when they did the reading aloud assignment, 4 subjects have a low score in four section of Rasinski scale. They monotonously read the text, with a little sense of making the text sound like a natural language, often read word-by-word, makes frequent prolonged pauses and sounds hesitate (usually when they met unfamiliar words), read slowly and laboriously. 5 other subjects read slightly better in phrasing and pace but fail to show appropriate expression and did not read smoothly the short passage.

After they read aloud the texts, the subjects were asked to answer the questions related to the given texts.

From the Table 2, 8 of 10 the students were able to answer correctly all of the questions. Further investigation revealed that these students did not understand many words within the texts; the researcher found out about their lack of comprehension by choosing a random word and asked the students whether they know the meaning of that particular word (ex. What is the word "soak" means?). These students failed to answer. The researcher found that most students were able to answer the questions not because they comprehended the texts, but because they had a sort of answer key in their book. The researcher solved this preference toward answer key by providing new short passages from another course book for the students.

To measure the students listening comprehension skill, the subjects were asked to do a listening comprehension assignment. 
From Table 3, 8 of 10 subjects were struggling with the listening session. 5 of the subjects chose 10 wrong answers out of 10 questions of the listening comprehension test. The recordings were a relatively short conversation by native speakers in conversational pace. The subjects were failed to decode meaning, had a low ability in word recognition, thus they couldn't answer the question correctly. 'They speak too fast' is the most common reason made by the students regarding their low score.

\section{DISCUSSION}

The aim of the study is to found out the role of prosody in reading fluency and comprehension. The researcher measured the prosodic reading skill by assigning the students to read aloud short texts. From the reading aloud assignment, it was found that prosody is a reliable sign to determine students' reading comprehension and clearly shown student's reading fluency. When students read monotonously instead of making

Table 1. Result of Reading Aloud Assignment

\begin{tabular}{|c|c|c|c|c|c|}
\hline \multirow[t]{2}{*}{ Participants } & \multicolumn{4}{|c|}{$\begin{array}{l}\text { Multidimensional Fluency Scale } \\
\text { (Rasinski, 2004) }\end{array}$} & \multirow[t]{2}{*}{ Score } \\
\hline & Expression and volume & Phrasing & Smoothness & Pace & \\
\hline Subject 1 & 1 & 1 & 1 & 1 & 4 out of 16 \\
\hline Subject 2 & 1 & 1 & 1 & 1 & 4 out of 16 \\
\hline Subject 3 & 2 & 2 & 2 & 2 & 8 out of 16 \\
\hline Subject 4 & 1 & 2 & 1 & 2 & 6 out of 16 \\
\hline Subject 5 & 1 & 1 & 1 & 1 & 4 out of 16 \\
\hline Subject 6 & 2 & 2 & 2 & 2 & 8 out of 16 \\
\hline Subject 7 & 2 & 3 & 2 & 3 & 10 out of 16 \\
\hline Subject 8 & 1 & 1 & 1 & 1 & 4 out of 16 \\
\hline Subject 9 & 1 & 2 & 2 & 2 & 7 out of 16 \\
\hline Subject 10 & 2 & 2 & 1 & 2 & 7 out of 16 \\
\hline
\end{tabular}

Table 2. Result of answering the questions related to the text

\begin{tabular}{ll}
\hline Participants & Number of correct answer \\
\hline Subject 1 & 5 out of 5 questions \\
Subject 2 & 5 out of 5 questions \\
Subject 3 & 5 out of 5 questions \\
Subject 4 & 5 out of 5 questions \\
Subject 5 & 4 out of 5 questions \\
Subject 6 & 5 out of 5 questions \\
Subject 7 & 5 out of 5 questions \\
Subject 8 & 4 out of 5 questions \\
Subject 9 & 5 out of 5 questions \\
Subject 10 & 5 out of 5 questions \\
\hline
\end{tabular}

Table 3. Result of listening comprehension assignment

\begin{tabular}{ll}
\hline Participants & Number of correct answer \\
\hline Subject 1 & None \\
Subject 2 & None \\
Subject 3 & 4 out of 10 questions \\
Subject 4 & 3 out of 10 questions \\
Subject 5 & None \\
Subject 6 & 6 out of 10 questions \\
Subject 7 & 8 out of 10 questions \\
Subject 8 & None \\
Subject 9 & 4 out of 10 questions \\
Subject 10 & None \\
\hline
\end{tabular}


the reading sounds like a natural language, read word-byword, makes frequent prolonged pauses and sounds hesitate, the reading process is requiring a lot of time and effort, he/ she unable to comprehend the meaning of the text, they may recognize a word, know how to spell it but they fail to read with appropriate expressions, fail to see the proper boundaries of clause, thus they fail to construct meaning from the text.

The students' reading fluency and comprehension are usually measured solely by their ability to answer the questions related to the text, but this study revealed that although the students are able to answer all of the questions correctly, it does not necessarily mean that the students comprehend the text. The ESL students' sample in the current study has the answer key sheet. And from observations in several meetings, the preference toward this answer key is relatively strong amongst the students. This result implies that hearing prosodic features in reading aloud task is the more reliable measurement to see the students reading fluency and comprehension compared to answering questions related to the text.

The current study also denotes that limited ability in prosodic reading also closely related with limited capacity to comprehend spoken text. The five subjects (Participant number 1,2,5,8 and 10) who had the lowest score in prosodic reading in Table 1 were also the same subjects who couldn't give any correct answer in the listening comprehension test in Table 3. So, the receptive skills in language acquisition (reading and listening comprehension skills) are closely related.

\section{CONCLUSION AND SUGGESTION}

These participants are undergraduate students, they were all adult female and male who have learned English in school (at the very least twice a week) for more than 12 years. With such a low capability to do prosodic reading and listening comprehension test, English teachers for ESL students need to improve learning process in class. This study shows reading aloud assignment is a more reliable tool to measure students' reading comprehension skill than answering multiple choice question assignment.

Students who need a lot of time and effort when they read is rarely succeed in their academic life and they seldom read for recreational goals (Moats, 2001). Fuchs et al. (2001) proposed that "oral reading fluency [i.e. rate and accuracy] serve as a portrayal from many complex aspects in students' capacity" (p. 239) that captures a various processes related to reading: connecting what they see to the sound they hear, decoding the word meanings, seeing the relation of words within sentences, relating text they read with their prior knowledge, and making conclusions. Thus, the prosodic features in reading is considered as an important measurement of reading proficiency and a tool to monitor improvement, just like a thermometer as a tool for measuring the temperature and ongoing changes (Shinn, Good, Knutson, \& Tilly, 1992).

There are some research-based instructional methods to develop fluency that is applicable in the classroom with struggling readers like this research participants.

- The teacher should be able to model fluent oral reading (Blevins, 2001; Rasinski,2003; Chard et al., 2002).
- Provide instruction and feedback to teach decoding of unknown words, proper expression and phrasing, the return-sweep eye movement, and other strategies used by fluent readers (NICHD, 2000; Snow et al., 1998).

- Facilitate different ways to support the development of oral reading skills (Rasinski, 2003) using assisted reading, choral reading, paired reading, recorders, and computer programs.

- Provide students with various of materials at their reading level to read on their own (Allington, 2000).

- Provide a lot of chances for practicing with repeated readings at their own level to a progressively more difficult text (Chard et al., 2002; Meyer \& Felton, 1999; Rasinski, 2003).

Prosody as a research topic offers a lot of interesting topics to study. For further study, it should be interesting to find out whether prosodic reading is the best approach to teach reading in the ESL classroom. And whether prosodic contribute something to students' long term memory.

There is some limitation of the study, the number of participants in this study was relatively small, and averagely have the same age, females, and males young adult in their 20 ies. A wider range of age of participants may contribute different result of this study. The reading materials were in similar form, descriptive and narrative texts, a different kind of reading material such as dialogues or poem should be more inviting for students to read with prosodic features.

\section{REFERENCES}

Frazier, L., Carlson, K., \& Clifton, C. J. (2006). Prosodic phrasing is central to language comprehension. Trends in Cognitive Sciences. http://dx.doi.org/10.1016/j. tics.2006.04.002

Klauda, S. L., \& Guthrie, J. T. (2008). Relationships of three components of reading fluency to reading comprehension. Journal of Educational Psychology. http://dx.doi. org/10.1037/0022-0663.100.2.310

Kuhn, M. R., Schwanenflugel, P. J., \& Meisinger, E. B. (2010). Aligning theory and assessment of reading fluency: Automaticity, prosody, and definitions of fluency. Reading Research Quarterly, 45, 230-251. http://dx.doi. org/10.1598/rrq.45.2.4

Rasinski, T. V. (2004). Creating fluent readers. Educational Leadership, 61, 46-51.

Rasinski, T., Rikli, A., \& Johnston, S. (2009). Reading fluency: More than automaticity? More than a concern for the primary grades? Literacy Research and Instruction, 48, 350-361. http://dx.doi. org/10.1080/19388070802468715

Schreiber, P. A. (1991). Understanding prosody's role in reading acquisition. Theory into Practice, 30, 158-164. http://dx.doi.org/10.2307/1476877

Philips, D. (2004) Longman preparation Course for the TOEFL test. New York: Pearson Education ESL.

Wennerstrom, A.K. (2001) The music of everyday speech: Prosody and discourse analysis. New York: Oxford University Press. Pp. xix, 317 